\title{
BONE LESIONS OF URTICARIA PIGMENTOSA IN CHILDHOOD
}

\author{
BY \\ MARTIN H. LEES and C. ERIC STROUD \\ From The Hospital for Sick Children, Great Ormond Street, London
}

(RECEIVED FOR PUBLICATION NOVEMBER 4, 1958)

Urticaria pigmentosa is a dermatosis characterized clinically by areas of pigmented skin which show marked urtication when a stimulus such as a scratch or a pinprick is applied. Initially they occur as pink urticarial lesions, but instead of fading they persist as oval or round, light or dark brown macules or, less commonly, papules or nodules.

Histologically, the skin lesions show an increased number of mast cells in the dermis, and probably it is their high histamine content which accounts for the facility with which urtication occurs. The mast cells contain not only an abnormally high content of histamine (Riley, 1953; Riley and West, 1953), but also a great excess of heparin (Oliver, Bloom and Mangieri, 1947).

In recent years the concept of a generalized disease due to mast cell proliferation has been gaining ground. Mast cell infiltration of parenchymatous organs has been reported (Ellis, 1949; Reilly, Shintani and Goodman, 1955; Berlin, 1955; Brodeur and Gardner, 1956; Loewenthal, Schen, Berlin and Wechsler, 1957; Rider, Stein and Abbuhl, 1957), and the appearance of mast cells in the peripheral blood has been called a mast cell leukaemia (Hissard, Moncourier and Jacquet, 1950; Waters and Lacson, 1957).

The discovery by Sagher, Cohen and Schorr (1952) that bone lesions could be associated with urticaria pigmentosa has led others to investigate the condition from this aspect (Clyman and Rein, 1952; Calnan, 1953; Asboe-Hansen, 1953; Grupper, 1954; Parmentier, 1954; Bluefarb and Salk, 1954; Cordero, 1954; Degos, 1955; Reilly et al., 1955; Stark, Van Buskirk and Daly, 1956; Deutsch, Ellegast and Nosko, 1956; Schorr, Sagher and Liban, 1956; Sagher, Liban, Ungar and Schorr, 1956; Zak, Covey and Snodgrass, 1957).

These accounts show a striking variability in the incidence of osseous abnormalities and also in the form and characteristics of the lesions.

The admission of an 8-year-old girl with urticaria pigmentosa, paraplegia and bone changes in the spine (Case 1) led us to re-examine 31 other children, who had been patients at this hospital, with a diagnosis of urticaria pigmentosa.

\section{Scope of the Survey}

Questions were put to the parents of each child concerning the onset, course and behaviour of the skin disorder. A history suggestive of intermittent or continuous release of histamine or heparin was sought.

Physical examination of each child was made with particular reference to evidence of coagulation disorder, hepatomegaly, splenomegaly, or clinical evidence of bone involvement.

A skeletal survey consisted of a lateral radiograph of the skull, an anteroposterior view of the chest, and single radiographs of the dorsal and lumbar spine, and of the upper and lower limbs. Haematological evidence of a coagulation disorder was sought; in all patients, haemoglobin, bleeding-time and clotting-time were estimated. The serum cholesterol was also estimated in each case. In those with evidence of systemic or bony abnormality the urine was examined for excess 5-hydroxyindoleacetic acid, as this metabolite of serotonin has been found in excess in cases of systemic mast cell disease.

Thirty-two children were examined. Four showed unequivocal bony abnormalities (Cases 1-4), one of whom also had an enlarged spleen. Case 5 had associated coeliac disease together with generalized osteoporosis. Case 6 had gross hepatomegaly, thought to be the result of bacterial cholangitis. Case 7 had unexplained splenomegaly.

\section{Case Histories}

Case 1. P.W., an $8 \frac{1}{2}$-year-old white girl, was admitted to this hospital under the care of Dr. Wilfrid Sheldon on August 6, 1957. Most of her life had been spent in Mombasa, Kenya. She had three healthy siblings.

At the age of 1 week she developed blotchy patches 
on the skin of her trunk, neck and limbs; these were at first red but subsequently became brown and now are seen to have all the characteristics of urticaria pigmentosa.

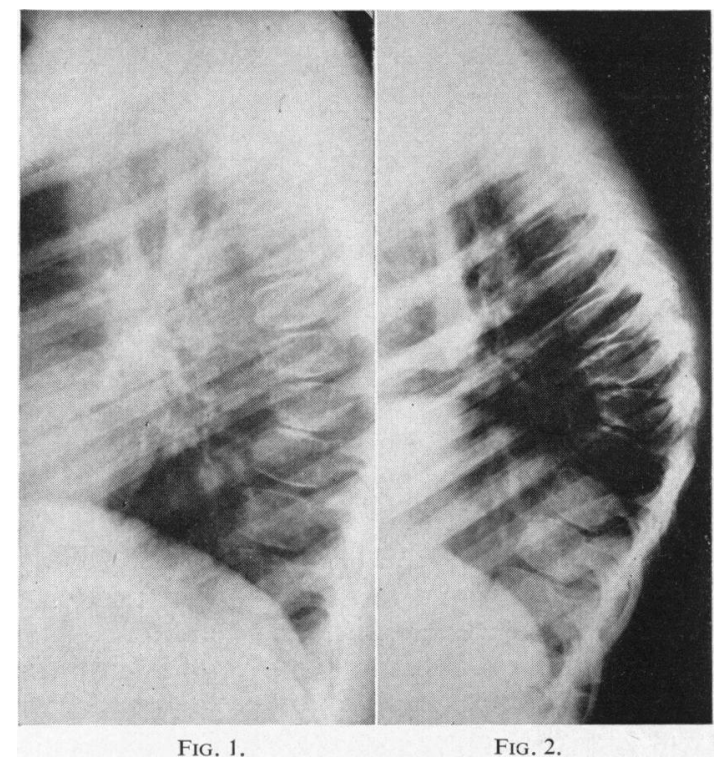

FIG. 1.-Case 1. Thoracic spine, showing appearances similar to Scheuermann's disease (August, 1957).

FIG. 2.-Case 1. Thoracic spine (January, 1958).

When 2 years old she had a febrile illness lasting eight weeks, during which she lost the use of both legs and partially of her right arm. She made a complete recovery except for slight weakness of her right leg, which caused a persistent limp.

She remained well until the age of 7 years 11 months, when her right leg became weaker and she started falling down. Four months later her left leg also became weak and she had progressive difficulty in walking; shortly afterwards there was difficulty in starting micturition. In the two weeks before admission to hospital she complained of pins and needles in both legs.

She was a cheerful, intelligent girl. Her skin showed unequivocal urticaria pigmentosa. In the central nervous system there were signs of spastic paraplegia more marked on the right than on the left, with sensory loss involving the posterior columns and spinothalamic tracts, but with no definite sensory level. Tendon reflexes were very brisk in both legs, the right side more so than the left; there were bilateral extensor plantar responses. She was just able to walk unaided and her gait was typically spastic; other systems were entirely normal.

Radiographs of the spine showed a mid-dorsal kyphosis with wedging of the bodies of $\mathrm{T} 7$ and $\mathrm{T} 8$ and narrowing of the adjacent disc spaces. The anterior parts of these two vertebral bodies were involved by an osteolytic process, similar in appearance to Scheuermann's disease. Skeletal survey was otherwise negative.
Haemoglobin was $100 \%$, Mantoux negative to $1: 100$ and W.R. negative. Bone marrow was normal. No excess 5-hydroxyindoleacetic acid was discovered in the urine. Bleeding and clotting times were normal. Cerebrospinal fluid was under $200 \mathrm{~mm}$. pressure, the child was rather upset by the procedure and Queckenstedt's test was not conclusive. A myelogram on August 15, 1957, showed that there was an arachnoid cyst situated posterior to the spinal cord, extending from T7 to T11. It communicated with the subarachnoid space below.

A skin biopsy was taken at the time of myelography and showed the typical appearances of urticaria pigmentosa.

A laminectomy was performed by Mr. Kenneth Till. It was possible to remove approximately nine-tenths of the cyst, leaving the subarachnoid space entirely free of obstruction.

Microscopy of the cyst wall showed that it was formed of collagenous tissue, containing scanty fibroblasts and a few polymorphs, but no mast cells. The bone fragments from laminectomy were also examined microscopically but showed no mast cell infiltration. The area of bone involved by the osteolytic process was on the anterior surfaces of the vertebrae and was not available for biopsy.

Post-operatively, her walking appeared to improve, though the physical signs were unchanged, apart from an increase in her dorsal kyphosis.

Five months post-operatively it was evident that her walking was deteriorating and a repeat myelogram showed that there was again a partial block at the level

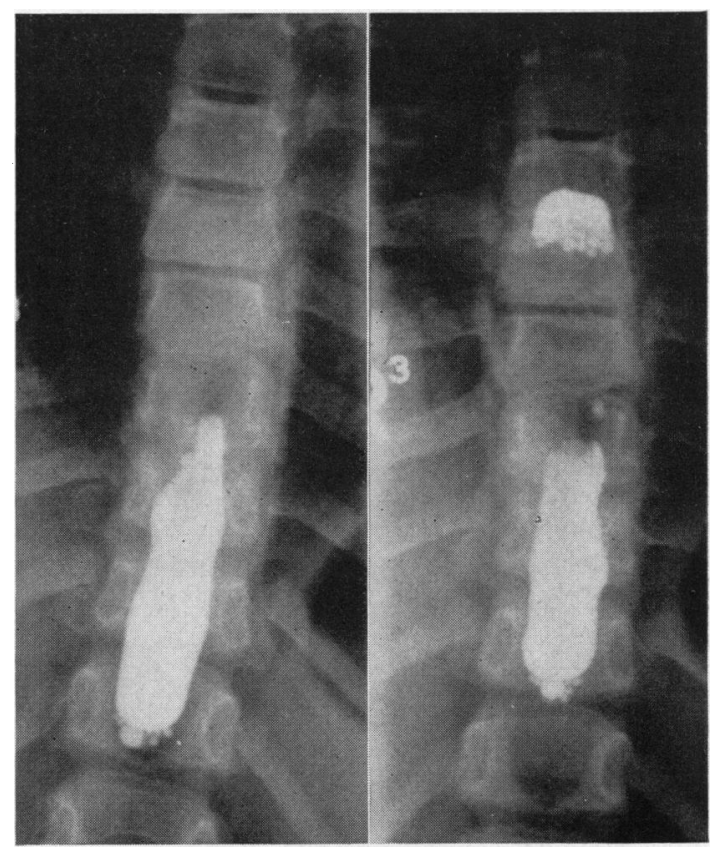

FIG. 3.-Case 1. Myelogram. August, 1957. Showing arachnoid cyst extending from T.7 to T.11. 
of T9 and the contrast medium again filled the cyst which was previously demonstrated.

On January 29, 1958, Mr. Kenneth Till carried out a further laminectomy of T6, T7 and T11. The cyst was this time lined with a membrane much thicker and more opaque, and was also more extensive, reaching up to T7 and down to T12. It was possible to remove only a small portion of the cyst.

Post-operatively she was seen by Dr. I. G. Williams who thought that in view of the poor prognosis irradiation was justified, accepting the hazard of producing a radiation myelitis. Irradiation was therefore given.

Three months after the second operation she is definitely walking better, though there has still been little change in the physical signs.

Case 2. L.P., 10-year-old girl, developed urticaria pigmentosa at the age of 5 months. When aged 8 years she started to complain of abdominal pains, vaguely related to meals. A barium meal was normal, but the spine showed the appearances of Scheuermann's disease affecting the vertebral bodies T7, T8 and T9 (Fig. 4). Bone marrow was normal. Haemoglobin was $83 \%$ and bleeding and clotting times were normal. Serum cholesterol was $197 \mathrm{mg}$. \%.

There was no kyphosis and the deformity of the vertebral bodies did not appear to cause any disability.

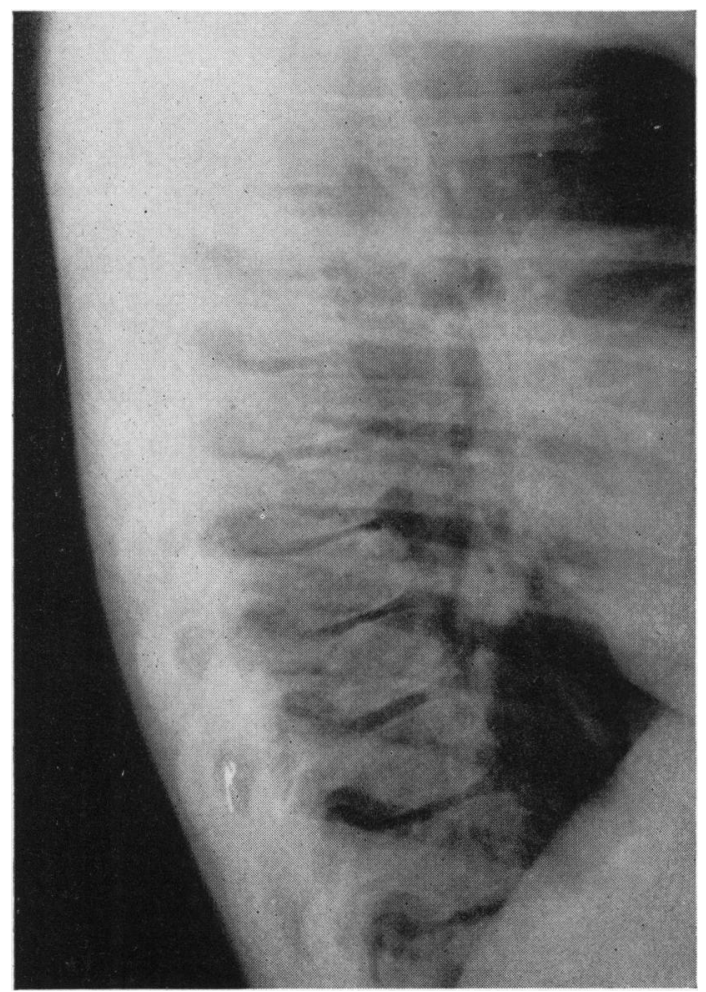

FIo. 4.-Case 2. Thoracic spine, showing appearances similar to Scheuermann's disease.
The abdominal pain of which she occasionally complained had none of the characteristics of root pain.

Case 3. S.B., a 3-year-old-girl, developed urticaria pigmentosa a few weeks after birth. Her general health

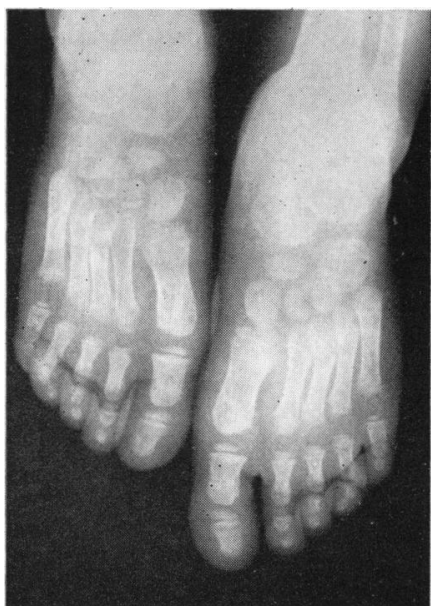

FIG. 5.

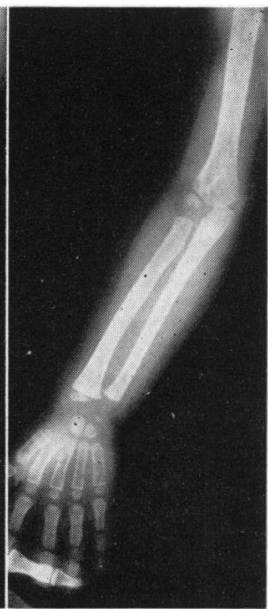

FIG, 6.
Fig. 5.-Case 3. Radiograph of feet, showing osteoporosis

FIG. 6.-Case 3. Radiograph of arm, showing osteoporosis.

was excellent, except for occasional vomiting bouts. On physical examination her liver was found to be enlarged to $5 \mathrm{~cm}$. below the right costal margin and the spleen palpable $3 \mathrm{~cm}$. below the left costal margin.

Skeletal survey showed generalized osteoporosis (Figs. 5,6 . Serum cholesterol was $127 \mathrm{mg}$. \% and the haemoglobin $82 \%$. Bleeding and clotting times were normal.

Case 4. J.A., an 11-year-old boy, developed urticaria pigmentosa at the age of 3 months. No abnormality was found on physical examination, but radiographs of the knees showed increased tubulation at the ends of the femora, and on the medial aspects there were small exostoses.

Case 5. S.D., a 2-year-old girl, developed urticaria pigmentosa at the age of 3 months. Birth weight was $6 \mathrm{lb}$. $6 \mathrm{oz}$., and at the age of $8 \frac{1}{2}$ months she was admitted to this hospital under the care of Dr. B. E. Schlesinger for investigation of failure to thrive; she weighed only $10 \mathrm{lb} .13 \mathrm{oz}$

A diagnosis of coeliac disease was made and she was put on a gluten-free diet. She gained $3 \mathrm{lb}$. in the next month and a further $4 \mathrm{lb}$. in the next four months. Skeletal survey showed generalized bone decalcification which has reverted to normal after treatment on a glutenfree diet.

Case 6. R.G., a 13-month-old boy, was admitted to this hospital under the care of Professor A. A. Moncrieff with an eight-week history of fever, anorexia and 
drowsiness. On admission his temperature was $103 \cdot 4^{\circ} \mathrm{F}$., his liver was enlarged $7 \mathrm{~cm}$. below the right costal margin and urticaria pigmentosa was present.

Mr. H. H. Nixon performed a laparatomy; there were several ounces of free fluid in the peritoneal cavity, and the liver was uniformly enlarged and firm.

Dr. Martin Bodian reported that a skin biopsy confirmed the diagnosis of urticaria pigmentosa and that liver biopsy showed the appearances of a bacterial cholangitis with excessive numbers of histiocytic reticulum cells. No mast cells were seen.

Dr. I. A. B. Cathie reported on the bone marrow; the smear taken before treatment showed marked toxic granulation of myelocytes, giving appearances very similar to the mast cells described in cases of mast cell leukaemia (Hissard et al., 1950; Waters and Lacson, 1957). However, the granules did not stain heavily with toluidine blue and the marrow reverted to normal following antibiotic therapy.

Treatment was begun with intramuscular penicillin and streptomycin, and continued with Gantrisin. The temperature returned to normal, the liver rapidly diminished in size, and so a diagnosis of bacterial cholangitis appeared to be substantiated.

The case shows a clinical similarity to that reported by Rider et al. (1957) where a $2 \frac{1}{2}$-year-old girl presented with urticaria pigmentosa, fever and hepatosplenomegaly. In their case, however, there were mast cells in the bone marrow and 25-30 mast cells per high power field in the liver: there was improvement without antibiotic therapy.

The clinical picture of Case 6 is unusual since, in spite of gross enlargement of the liver, there was no jaundice, neither was there any alteration in the liver function tests, as is usual with bacterial cholangitis associated with hepatomegaly of this degree. Final judgment on the relationship, if any, between this child's urticaria pigmentosa and his liver disease cannot yet be made.

Case 7. G.W., a 2-year-old boy, developed urticaria pigmentosa at the age of three days. The rash spared only the hands; on the buttocks it tended to be confluent, but elsewhere was in the form of macules $\frac{1}{2}-1 \mathrm{~cm}$. in diameter. The spleen was palpable $1 \mathrm{~cm}$. below the left costal margin, but otherwise there was no abnormality. Haemoglobin was $84 \%$. Bone marrow showed a highly active but normal picture. Skeletal survey showed no abnormality.

\section{Discussion}

Urticaria pigmentosa is described in most text books of dermatology as a harmless but interesting dermatosis, occurring predominantly in children and usually undergoing spontaneous regression around the time of puberty.

In our series, 29 of the 32 gave a history of onset between the age of 3 weeks and 6 months; the other three arising at 10 months, 1 year and 6 years respectively.

Eight children were seen over the age of 10 years. In five of these the lesions had gone and in two the condition had much improved. In only one had the lesions persisted unchanged. This confirms the favourable prognosis usually given that the rash will clear up at, or before, puberty.

The form of the lesions seems to fall into three groups. They may be deeply pigmented, small, usually measuring less than $\frac{1}{4}$ in. in diameter, and situated mainly around the neck and shoulders (nine examples). Alternatively, the lesions are widespread, less pigmented, large, up to 2 in. in diameter, often confluent and involving chiefly the trunk and proximal parts of the limbs (22 examples). Rarely there is a solitary patch of urticaria pigmentosa; in one of our cases it was on the cheek. Our series included a pair of uniovular twins, both of whom showed urticaria pigmentosa. All the cases produced the characteristic urtication, following pinprick or scratch. No papular or nodular lesions were seen. Some of the cases had been verified by skin biopsy and nearly every case had been seen personally by Dr. R. T. Brain. Three had had wheezing attacks in the past, but antihistamine drugs had not been tried for their relief.

The striking variability of the bone lesions associated with urticaria pigmentosa has already been mentioned. Sagher and Schorr (1956) collected all the reported cases up to that time and found that they fell into two main groups. In one there was generalized cystic osteoporosis of the ribs with thickening of the bony trabeculae; stippling of the bony structure in the skull and thickening of the skull tables; generalized sclerosis of the pelvic bone and vertebrae. In the other, calcified deposits and decalcified areas of various sizes were seen in humerus, radius, femur, skull and shoulder.

The osteoporotic lesions found in Case 3 correspond well with the generalized type described by Sagher. The exostoses in Case 4 might well have nothing to do with the disease, but are nevertheless abnormal. The radiological changes similar to Scheuermann's disease in Cases 1 and 2 constitute a previously undescribed variant in the bone lesions of urticaria pigmentosa.

The presence of bone lesions in $12.5 \%$ of our cases of urticaria pigmentosa and in $36.5 \%$ of Sagher's series is strongly suggestive of a definite association and not of an incidental finding.

Unfortunately, none of the patients in our series has been suitable or willing to allow bone biopsy, but this has been carried out in three other reported cases. Stark et al. (1956) described a 55-year-old man in whom urticaria pigmentosa had been present since the age of 13 years: there were generalized radiological bone changes and a rib biopsy stained with toluidine blue and Giemsa-Wolbach showed 
many mast cells in the bone marrow. Zak et al. (1957) described a 58-year-old woman with urticaria pigmentosa and hepatosplenomegaly. Radiologically, the spine, thorax and pelvis were diffusely involved in a combined osteolytic-osteoblastic process, the appearances being highly suggestive of metastatic neoplasm. Bone from the right iliac crest stained with polychrome methylene blue (Unna) showed numerous mast cells.

Schorr et al. (1956) followed the case of a woman of 55. She had had a skin eruption diagnosed as urticaria pigmentosa for five years and on skeletal survey showed marked sclerosis of the whole of the bony structure of the vertebrae and pelvis. The radiographic bone changes were progressive and she died in July, 1955, after developing enlargement of liver, spleen and lymph nodes associated with monocytic leukaemia. Autopsy revealed osteosclerosis and myelosclerosis of bones and dense accumulations of mast cells in many of the marrow spaces. In addition there was monocytic infiltration of most of the internal organs and in the bone marrow.

Williams (1952) showed that tissue mast cells in small numbers are a normal constituent of human bone marrow and this is also the view of Johnstone (1956). They may be increased in numbers in a wide variety of pathological states, but the very great increase in the numbers of mast cells in the cases described by Stark et al., Zak et al. and Schorr et al., are surely indicative of an actual mast cell infiltration as the cause of the bony lesions.

\section{Summary}

A review of 32 children with urticaria pigmentosa disclosed four cases in which there were significant bone lesions. Two children showed changes similar to those seen in Scheuermann's disease, an association not previously described: in one of these there was an arachnoid cyst and paraplegia. A further three cases showed coincident abnormalities, coeliac disease in Case 5, bacterial cholangitis in Case 6 and unexplained splenomegaly in Case 7.

The incidence of osseous abnormalities is far greater than that to be expected from a random 32 children. The evidence for regarding these lesions as the result of mast cell infiltration is discussed.

For permission to report these cases and for helpful criticism, it is a pleasure to record our thanks to Dr. Wilfrid Sheldon, Professor A. A. Moncrieff, Dr. R. T. Brain and Dr. B. Schlesinger. We are also indebted to Dr. J. Sutcliffe, Dr. R. D. Hoare and Dr. G. N. Weber for their expert opinions in interpreting the radiographs, to Dr. Martin Bodian for the histological reports, and to Dr. I. A. B. Cathie for his opinion on the bone marrows. We thank also Mr. Derek Martin for the radiograph reproductions.

\section{REFERENCES}

Asboe-Hansen G. (1953). Acta derm.-venereol. (Stockh.), 33, 471. Berlin, C. (1955). A.M.A. Arch. Derm., 71, 703.

Bluefarb, S. M. and Salk, M. R. (1954). Ibid., 70, 376.

Brodeur, P. and Gardner, L. I. (1956). New Engl. J. Med., 254, 1165.

Calnan, C. D. (1953). Proc. roy. Soc. Med., 46, 544.

Clyman, S. G. and Rein, C. R. (1952). J. invest. Derm., 19, 179.

Cordero, A. (1954. Minerva derm. (Torino), 29, 55. Abst. Ann. Derm. Syph. (Paris), 82, 189.1955.

Degos, R. (1955). Act. dermo-sifiliogr. (Madr.), 46, 759.

Deutsch, E., Ellegast, H. and Nosko. L. (1956). Hautarzt, ? 257.

Ellis, J. M. (1949). Arch. Path. (Chicago), 48, 426.

Grupper, C. (1954). A.M.A. Arch. Derm. Syph., 69, 109.

Hissard, R., Moncourier, L. and Jacquet, L. (1950). C.R. Acad. Sci. (Paris), 231, 253.

Johnstone, J. M. (1956). Amer. J. clin. Path., 26, 60.

Loewenthal, M., Schen, R. J., Berlin, C. and Wechsler, L. (1957). A.M.A. Arch. Derm., 75, 512.

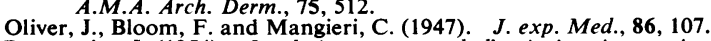

Parmentier, J. (1954). Les lesions osseuses de l'urticaire pigmentaire. Thèse, Paris.

Reilly, E. B., Shintani, J. and Goodman, J. (1955). A.M.A. Arch. Derm., 71, 561.

Rider. T. L., Stein, A. A. and Abbuhl, J. W. (1957). Pediatrics, 19,

Riley, J. F. (1953). Science, 118, 332.

and West, G. B. (1953). J. Physiol. (Lond.), 120, 528.

Sagher, F., Cohen, C. and Schorr, S. (1952). J. invest. Derm., 18 425.

Liban, E., Ungar, H. and Schorr, S. (1956). Ibid., 27, 355.

- Liban, E., Ungar, S. (1956). Ibid., 26, 431.

Schorr, S., Sagher, F. and Liban, E. (1956). Acta radiol. (Stockh.), 46, 575 .

Stark, E., Van Buskirk, F. W. and Daly, J. F. (1956). A.M.A. Arch. Path., 62, 143.

Waters, W. J. and Lacson, P. S. (1957). Pediatrics, 19, 1033.

Williams, G. T. (1952). Amer. J. clin. Path., 22, 1039.

Zak, F. G., Covey, J. A. and Snodgrass, J. J. (1957). New Engl. J. Med., 256, 56. 